\title{
Rancang Bangun Learning Management System Menggunakan Framework CodeIgniter Pada PT. Rekayasa Industri
}

\author{
Sumarna1, Mohammad Roffi Suhendry ${ }^{2}$, Eri Riana ${ }^{3}$, Verry Riyanto ${ }^{4}$, Hafis Nurdin ${ }^{5}$ \\ 1,2,4,5 STMIK Nusa Mandiri \\ 1e-mail: sumarna@nusamandiri.ac.id \\ 2e-mail: mohammad.roffi13@gmail.com \\ ${ }^{4}$ verry.vry@nusamandiri.ac.id \\ ${ }^{5}$ hafis.nnr@nusamandiri.ac.id \\ ${ }^{3}$ Universitas Bina Sarana Informatika \\ e-mail: eri.eea@bsi.ac.id

\begin{tabular}{ccc}
\hline Diterima & Direvisi & Disetujui \\
$06-10-2020$ & $11-10-2020$ & $25-01-2021$ \\
\hline
\end{tabular}

\begin{abstract}
Abstrak - Dalam mendukung kinerja perusahaan yang efektif dan efisien, PT. Rekayasa Industri (Rekind) mengimplementasikan aktifitas training untuk meningkatkan kualitas dari potensi kerja yang dimiliki karyawan terhadap bidang pekerjaanya. Penerapan training yang masih dilakukan secara tatap muka menjadi salah satu indikator kendala pada perusahaan karna perusahaan memiliki site project yang berlokasi jauh dari home office sehingga menghabiskan waktu dan biaya tansportasi. Gaya belajar yang memiliki perbedaan pada tiap-tiap karyawan juga kurang mendukung pada penerapan training secara tatap muka. Materi yang digunakan dalam proses training masih belum tersimpan dengan efektif. Untuk itu penelitian ini dilakukan yang bertujuan untuk melakukan perancangan dan pembangunan sistem manajemen pembelajaran (e-learning) yang dapat mengakses dan menyimpan materi, serta memudahkan proses training secara online melalui website oleh karyawan dan instruktur. Metode yang digunakan dalam penelitian yaitu model pengembangan SCRUM yang meliputi: Product backlog, Sprint Backlog, Sprint, dan Working Increment of The Software. Hasil dari penelitian ini yaitu dapat membangun learning management system berbasis web dengan menggunakan framework codeigniter yang dapat diakses secara online serta memudahkan karyawan dan instruktur dalam melakukan proses training, sehingga dapat mengoptimalkan efisiensi kinerja pada perusahaan.
\end{abstract}

Kata Kunci: codeigniter, e-learning, learning management system, SCRUM, web programming.

Abstract - In supporting effective and efficient company performance, PT. Rekayasa Industri (Rekind) implements training activities to improve the quality of the work potential of employees in the field of work. The application of training that is still done face to face is one indicator of the constraints on the company because the company has a site project located far from the home office so that it consumes time and transportation costs. Learning styles that have differences in each employee also do not support the application of training face to face. The material used in the training process is still not effectively stored. For this reason, this research was conducted in order to design and build a learning management system (e-learning) that can access and store material, and facilitate the online training process through websites by employees and instructors. The method used in this research is the SCRUM development model which includes: Product backlog, Sprint Backlog, Sprint, and Working Increment of The Software. The results of this study are able to build a web-based learning management system using a codeigniter framework that can be accessed online and make it easier for employees and instructors to conduct training processes, so as to optimize the efficiency of performance at the company.

Keywords: codeigniter, e-learning, learning management system, SCRUM, web programming.

\section{PENDAHULUAN}

"PT. Rekayasa Industri (Rekind) merupakan salah satu perusahaan BUMN yang bergerak di bidang engineering, procurement, construction, dan commisioning (EPCC) (PT Rekayasa Industri, 2019)."
Mengingat bisnis rekind yang bergerak di bidang jasa, rekind wajib memiliki karyawan yang berkompetensi dibidangnya masing-masing agar dapat menyelesaikan proyek secara efisien.

"Metode belajar yang dilakukan sangat berpengaruh terhadap hasil pembelajaran. Metode belajar secara tatap muka dinilai masih memiliki 
kekurangan yaitu setiap karyawan memiliki gaya belajar yang berbeda (Teuku Fadjar Shadek, 2017)."

Selain itu, rekind memiliki karyawan yang berada disite proyek, dimana proyek tersebut kebanyakan berada di daerah terpencil, hal ini menjadi kendala jika karyawan harus kembali ke kantor pusat hanya untuk mengikuti training. Dilain sisi training merupakan kewajiban setiap karyawan untuk meningkatkan kompetensi.

"Keterbatasan waktu dan tempat dalam proses pembelajaran menjadi hambatan dalam meningkatkan kualitas belajar (Romindo, 2017)."

Salah satu solusi dari permasalahan tersebut adalah rekind harus memiliki sebuah platform atau sistem pembelajaran online (e-learning) guna menunjang kebutuhan training para karyawannya. Dengan e-learning, karyawan tidak diharusnya hadir di dalam kelas untuk melakukan sebuah training.

Berdasarkan latar belakang berikut maka penulis tertarik mengambil judul "Rancang Bangun Learning Managemenet System Menggunakan Framework CodeIgniter Pada PT. Rekayasa Industri”.

\section{MODEL PENGEMBANGAN SISTEM}

Model pengembangan scrum merupakan model yang penulis pilih dalam mengembangankan sistem ini.

SCRUM adalah bagian dari Agile Development, SCRUM sendiri memiliki kunci kebiasaan yaitu: focus pada jadwal yang telah ditentukan, mengerjakan sprint secara konsisten, setiap melakukan pengerjaan harus ditandai sebagai product backlog, melakukan sprint berdasarkan product backlog, hasil sprint merupakan tanggung jawab dari scrum master, tim wajib memutuskan produk-produk yang dapat dikembangkan, melakukan pertemuan yang membahas tentang produk dan jadwal pengerjaan, focus terhadap sprint (Ependi, 2018).

Tahapan-tahapan yang dilakukan dengan menggunakan model pengembangan scrum adalah sebagai berikut:

\section{Product backlog}

Pada tahap ini penulis mengumpulkan semua kebutuhan pengguna yang terdiri dari fitur yang wajib diselesaikan terlebih dahulu sesuai prioritas.

\section{Sprint Backlog}

"Sprint backlog merupakan tahap pengerjaan yang akan dilakukan guna memenuhi kebutuhan yang ditentukan pada product backlog (Dafitri \& Elsera, 2017).”

\section{Sprint.}

Pada tahap ini penulis menjelaskan kepada pihak perusahaan berupa prototype mengenai sistem yang akan dibangun berdasarkan dengan kebutuhan pengguna yang telah didefinisikan.

\section{Working Increment of The Software.}

Pada tahap ini penulis melakukan pengembangan terhadap learning management system sesuai dengan kebutuhan yang telah direncanakan dan dapat digunakan oleh pihak PT. Rekayasa Industri. Untuk melewati tahapan ini terdapat 3 proses yaitu:

a. Scrum Meeting, melakukan pertemuan antara tim pengembang dengan pihak perusahaan guna membahas permasalahan atau kendala yang dihadapi pada tahap pengembangan, kemudian mecari solusi dari kendala tersebut.

b. Increment merupakan proses pembuatan learning management system menggunakan framework codeigniter. Setelah proses pembuatan selesai selanjutnya penulis melakukan testing pada sistem, sudah sesuai atau tidak.

c. Demos, pada proses ini penulis memberikan panduan mengenai penggunaan learning management system kepada pihak perusahaan (Dafitri \& Elsera, 2017)

\section{HASIL DAN PEMBAHASAN}

Learning Management System atau biasa disebut LMS merupakan sebuah platform yang berguna untuk mengelola administrasi sebuah pelatihan atau pembelajaran dengan metode $e$ learning (Wibowo, Akhlis, \& Nugroho, 2015). LMS memungkinkan instruktur menyampaikan materi pembelajaran secara online dan dapat memonitor aktifitas peserta pelatihan (Dharmawan, 2020).

1. Product Backlog Item

Berikut ini merupakan product backlog item dari learning management system ini:

Tabel 1. Product Backlog Item

\begin{tabular}{|l|c|}
\hline \multicolumn{1}{|c|}{ Backlog Item dapat mengelola data } \\
\hline $\begin{array}{l}\text { Admin daser } \\
\text { useri) }\end{array}$ \\
\hline $\begin{array}{l}\text { Admin dan Trainer dapat } \\
\text { membuat dan } \\
\text { mendaftarkan trainee kedalam } \\
\text { course }\end{array}$ \\
\hline $\begin{array}{l}\text { Trainee dapat mendaftarkan } \\
\text { diri kedalam course }\end{array}$ \\
\hline $\begin{array}{l}\text { Manager dapat menyetujui } \\
\text { staff/trainee untuk mengikuti } \\
\text { training }\end{array}$ \\
\hline $\begin{array}{l}\text { Admin dan Trainer dapat } \\
\text { menyimpan materi dan trainee } \\
\text { dapat melihat }\end{array}$ \\
\hline $\begin{array}{l}\text { Admin dan Trainer dapat } \\
\text { membuat kuis }\end{array}$ \\
\hline
\end{tabular}




\begin{tabular}{|l|l|}
\hline $\begin{array}{l}\text { Admin dan Trainer dapat } \\
\text { melihat dan mencetak nilai kuis } \\
\text { dari trainee }\end{array}$ & 2 \\
\hline $\begin{array}{l}\text { Trainee dapat melihat dan } \\
\text { mencetak nilai kuis yang } \\
\text { diikuti }\end{array}$ & 2 \\
\hline
\end{tabular}

Sumber: PT. Rekayasa Industri

2. Use Case Diagram

Berikut ini merupakan use case diagram pada learning management system:

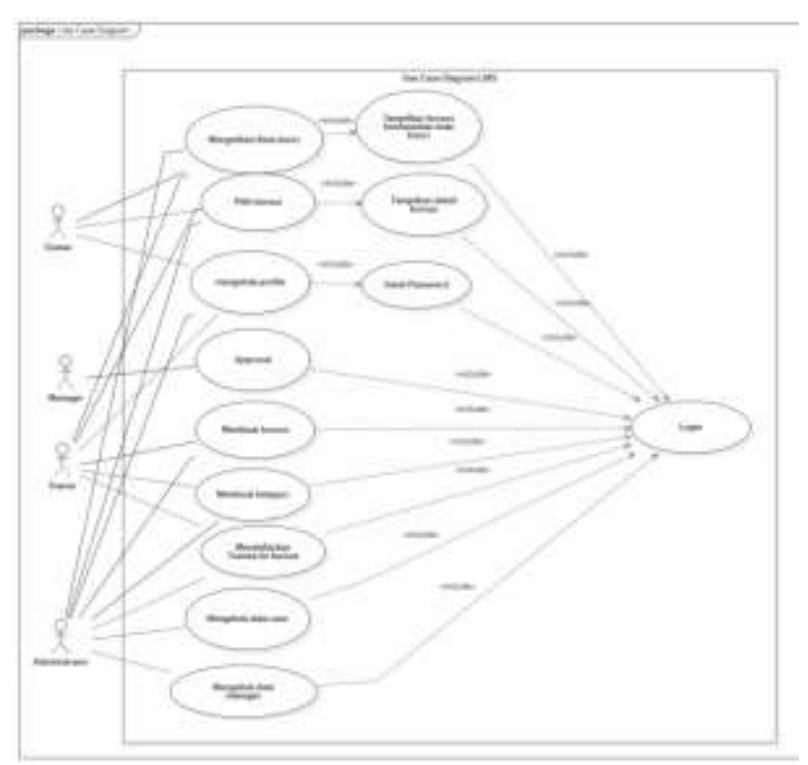

Sumber: Hasil Penelitian (2020)

Gambar 1. Use Case Diagram

Didalam sistem ini terdapat 3 role utama, yaitu: User, Instructor, dan Administrator, dan 1 privilege yaitu Manager. Manager ini merupakan privilege dari 3 role utama tersebut.

\section{Database}

"Database merupakan himpunan informasi yang disusun secara sistematis sehingga dapat diolah menggunakan software yang disimpan kedalam perangkat keras komputer (Swara, G. Y. Kom. M., \& Pebriadi, 2016)."

Menurut Connoly dan Begg dalam (Puspitasari, 2016), database merupakan kumpulan data yang saling berhubungan untuk memenuhi kebutuhan informasi dari suatu system.

a. Entity Relationship Diagram

Berikut ini merupakan ERD dari Learning Management System:

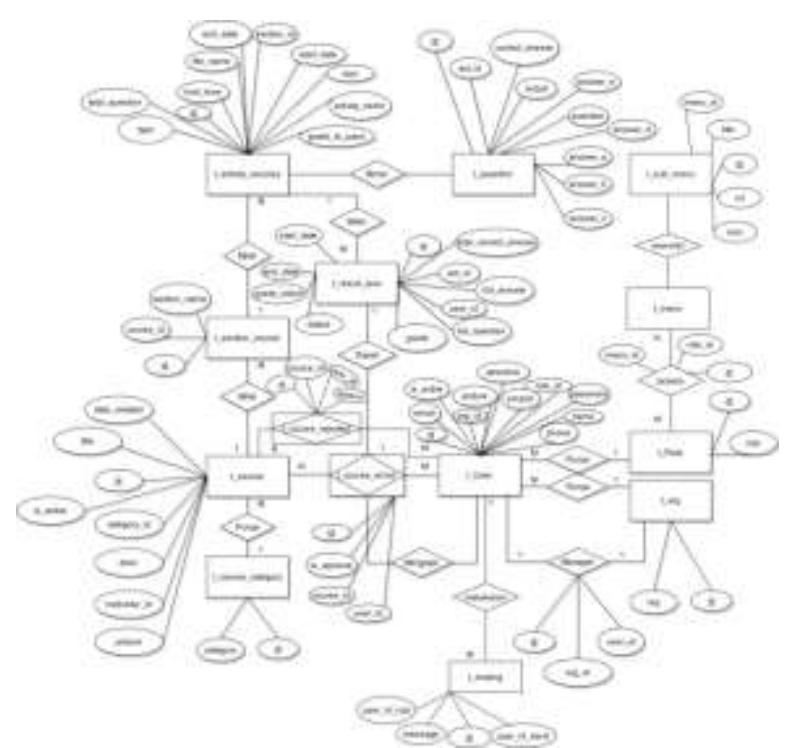

Sumber: Hasil Penelitian (2020)

Gambar 2. Entity Relationship Diagram

b. Logical Record Structure

Berikut Ini merupakan LRS dari Learning Management System:

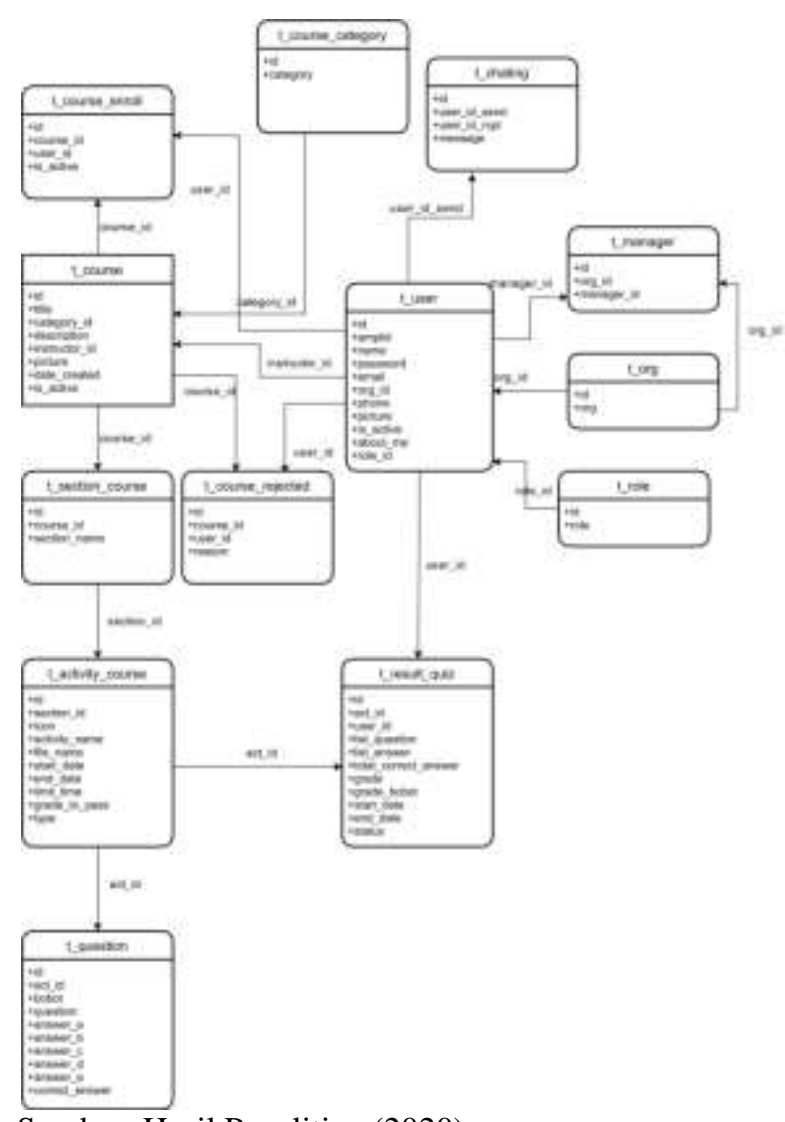

Sumber: Hasil Penelitian (2020)

Gambar 3. Logical Record Structure

4. User Interface 
Berikut ini merupakan user interface pada learning management system, sebagai berikut:

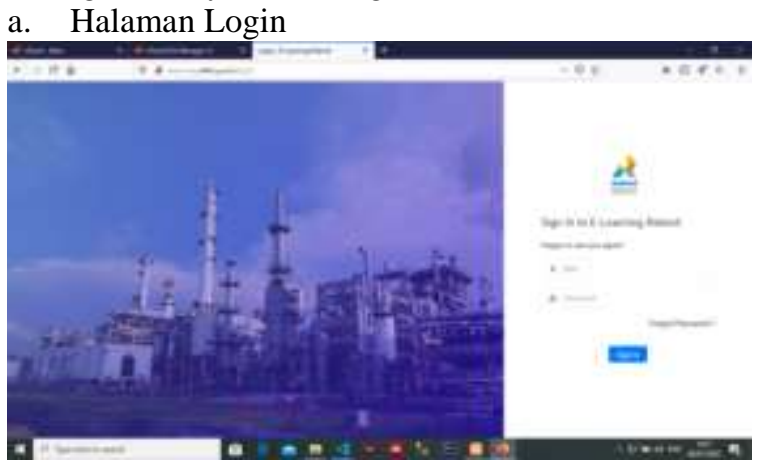

Sumber: Hasil Penelitian (2020)

Gambar 4. Halaman Login

b. Halaman List Course

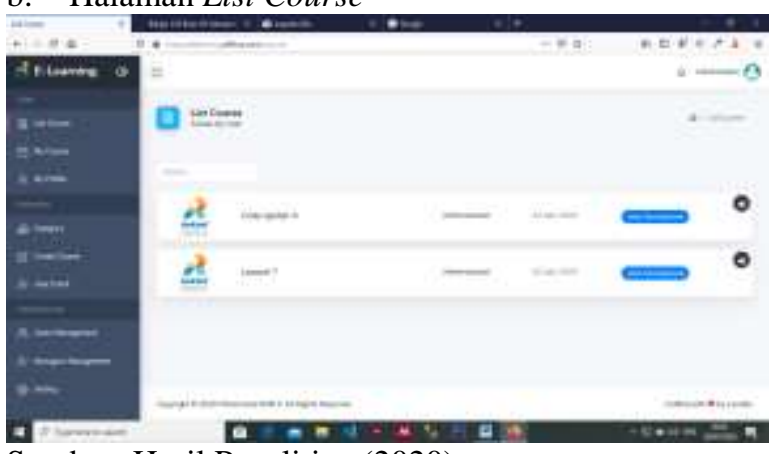

Sumber: Hasil Penelitian (2020)

Gambar 5. Halaman List Course

c. Halaman Course yang di Ikuti

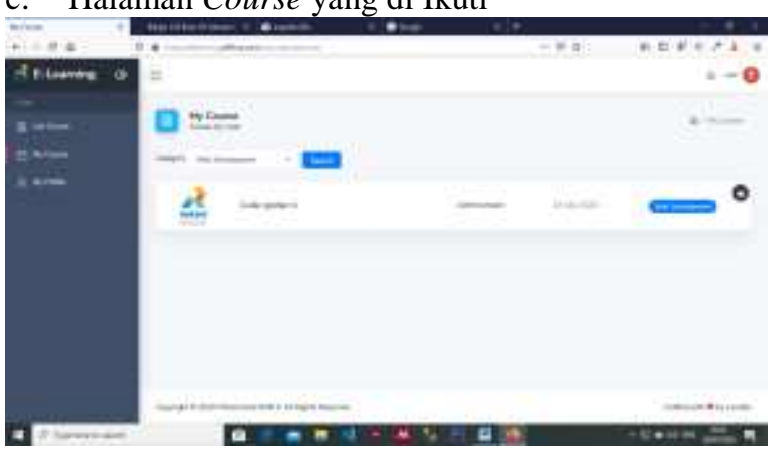

Sumber: Hasil Penelitian (2020)

Gambar 6. Halaman Course yang di Ikuti

d. Halaman Daftar User

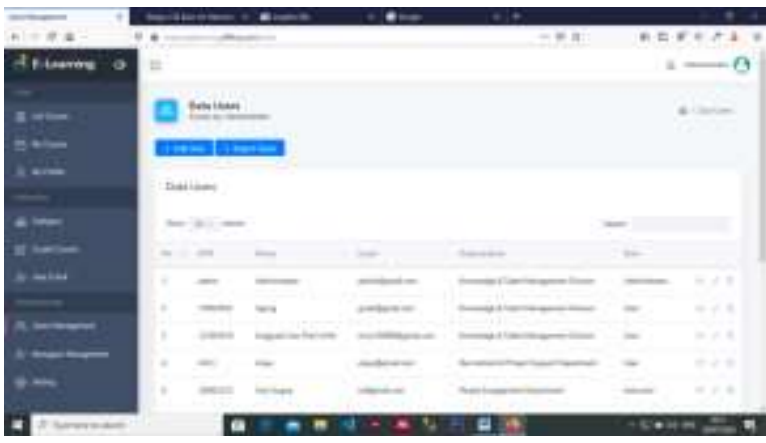

Sumber: Hasil Penelitian (2020)

Gambar 7. Halaman Daftar User e. Halaman Daftar Manager

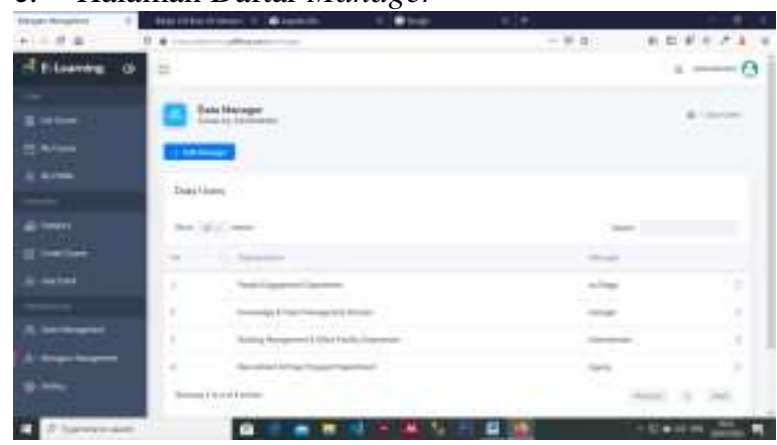

Sumber: Hasil Penelitian (2020)

Gambar 8. Halaman Daftar Manager

f. Halaman Membuat Course

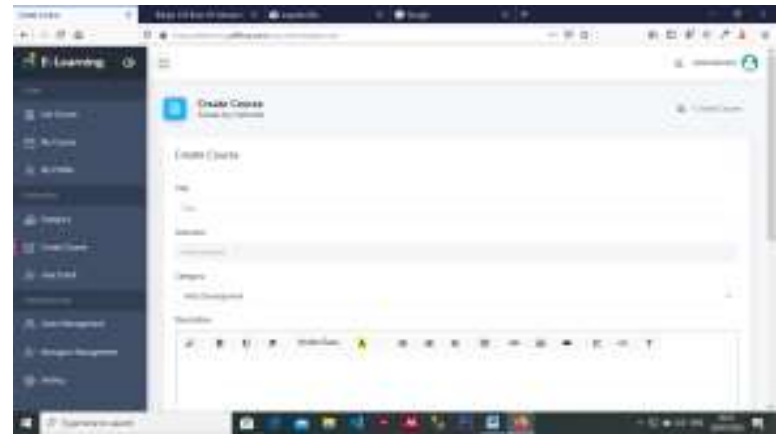

Sumber: Hasil Penelitian (2020)

Gambar 9. Halaman Membuat Course

g. Halaman Membuat Kategori

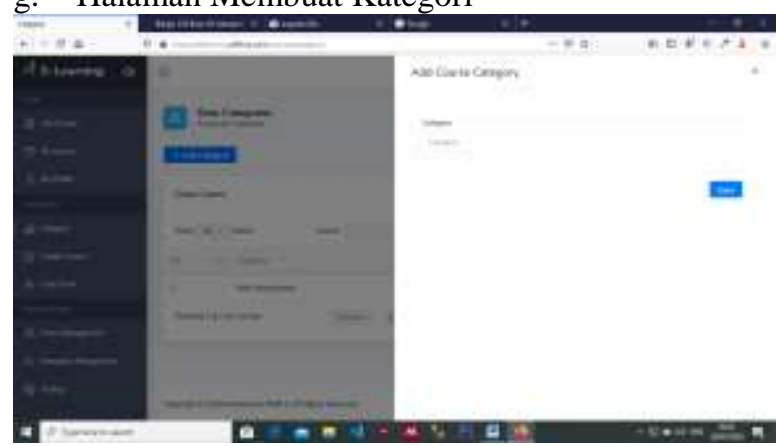

Sumber: Hasil Penelitian (2020)

Gambar 10. Halaman Membuat Kategori

h. Halaman Course

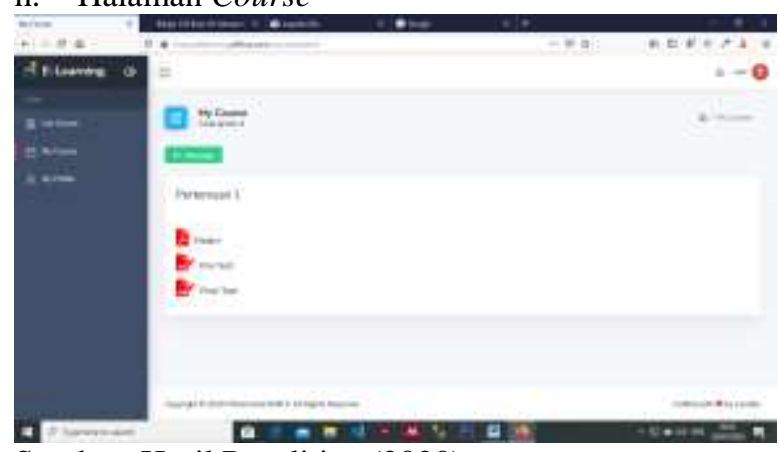

Sumber: Hasil Penelitian (2020)

Gambar 11. Halaman Membuat Kategori 
i. Halaman Activity Quiz

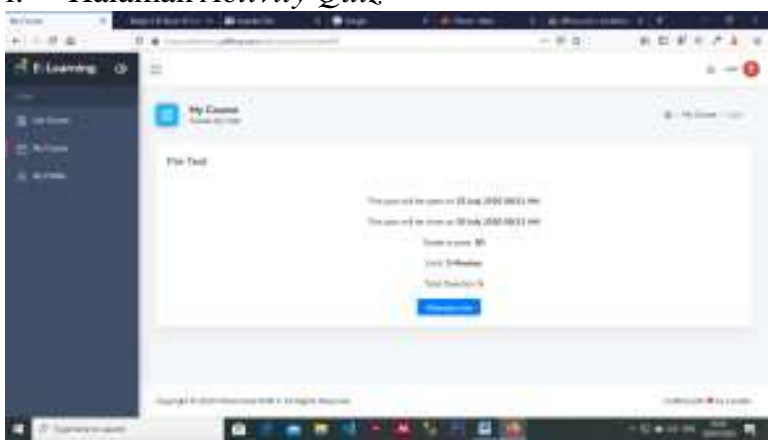

Sumber: Hasil Penelitian (2020)

Gambar 12. Halaman Membuat Kategori

j. Halaman Data Enroll Peserta

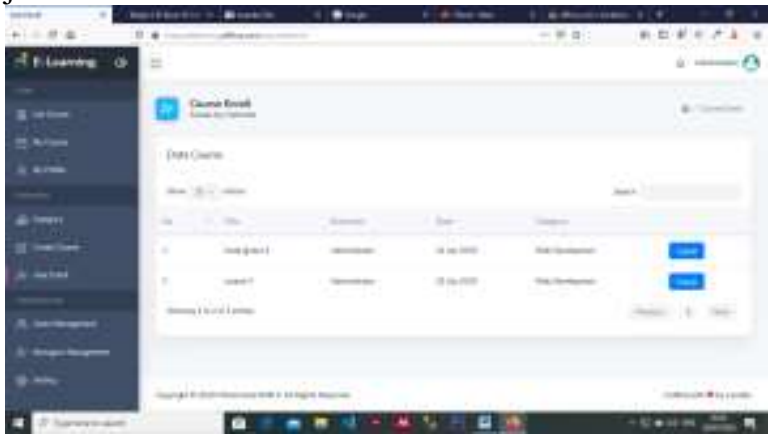

Sumber: Hasil Penelitian (2020)

Gambar 13. Halaman Data Enroll Peserta

k. Halaman Enroll Peserta

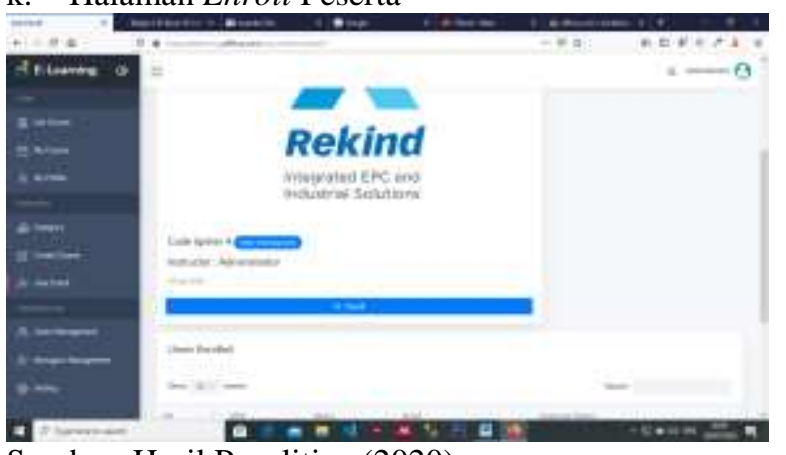

Sumber: Hasil Penelitian (2020)

Gambar 14. Halaman Enroll Peserta

\section{Halaman Menambah Materi}

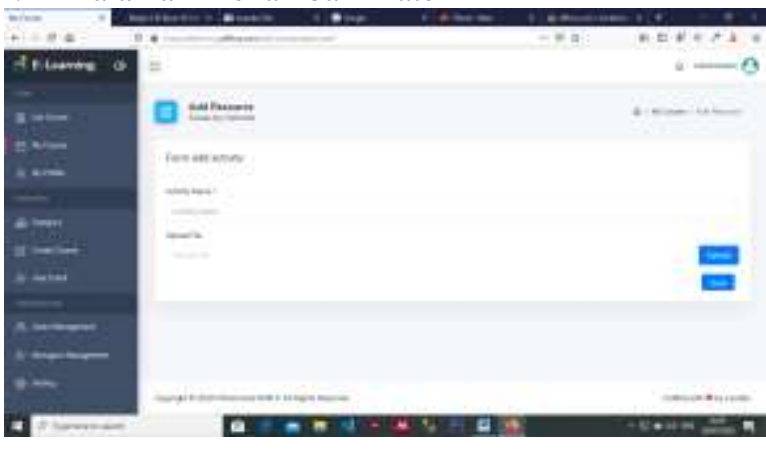

Sumber: Hasil Penelitian (2020)

Gambar 15. Halaman Menambah Materi

m. Halaman Menambah Pertanyaan

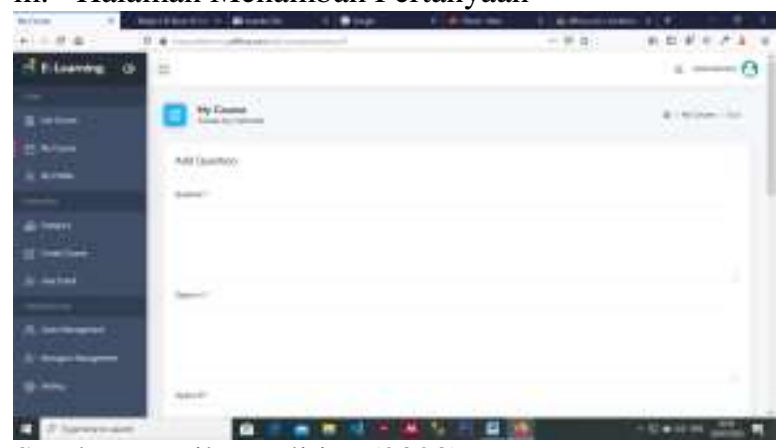

Sumber: Hasil Penelitian (2020)

Gambar 16. Halaman Menambah Materi

n. Halaman Menambah Quiz

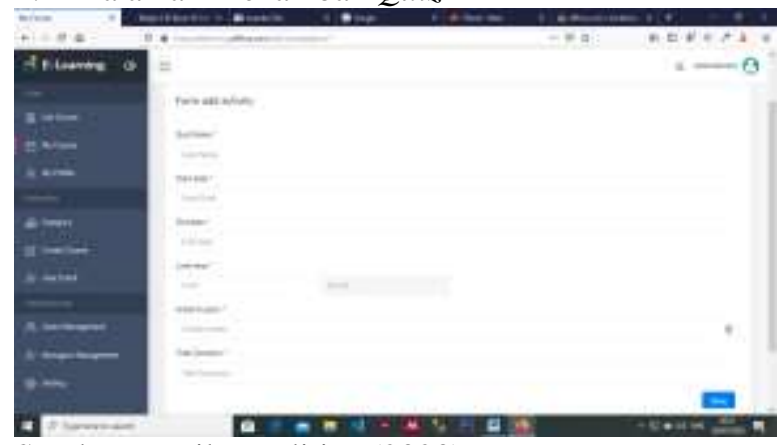

Sumber: Hasil Penelitian (2020)

Gambar 17. Halaman Menambah Quiz

o. Halaman Mengerjakan Quiz

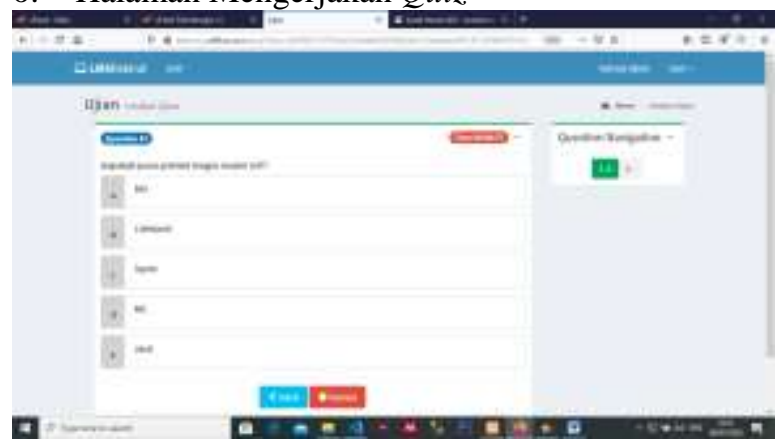

Sumber: Hasil Penelitian (2020)

Gambar 18. Halaman Mengerjakan Quiz

p. Halaman Report Nilai (Admin) 


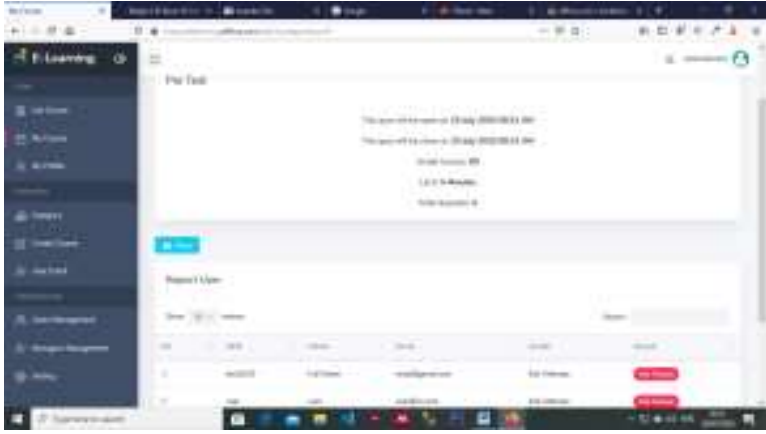

Sumber: Hasil Penelitian (2020)

Gambar 19. Halaman Report Nilai (Admin)

q. Halaman Report Nilai (User)

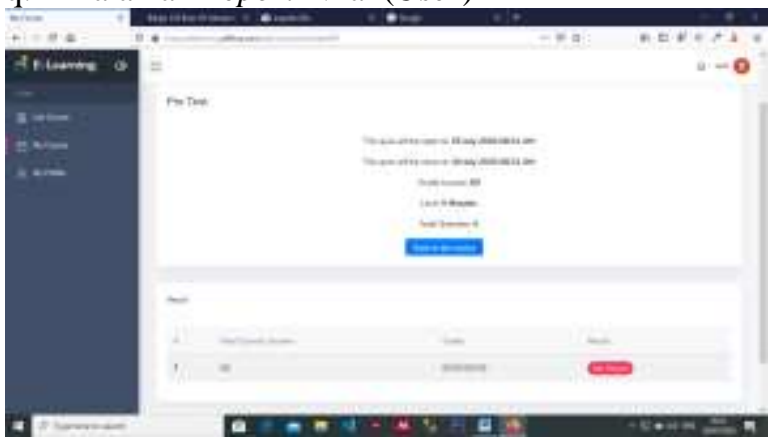

Sumber: Hasil Penelitian (2020)

Gambar 20. Halaman Report Nilai (User)

r. Halaman Tambah User

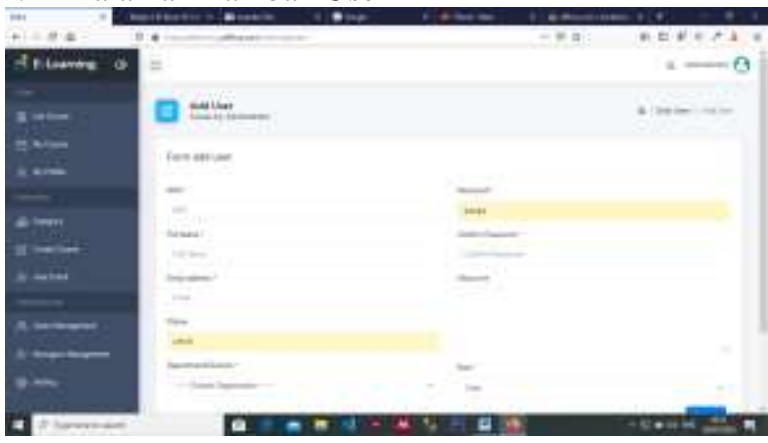

Sumber: Hasil Penelitian (2020)

Gambar 21. Halaman Tambah User

s. Halaman Import User

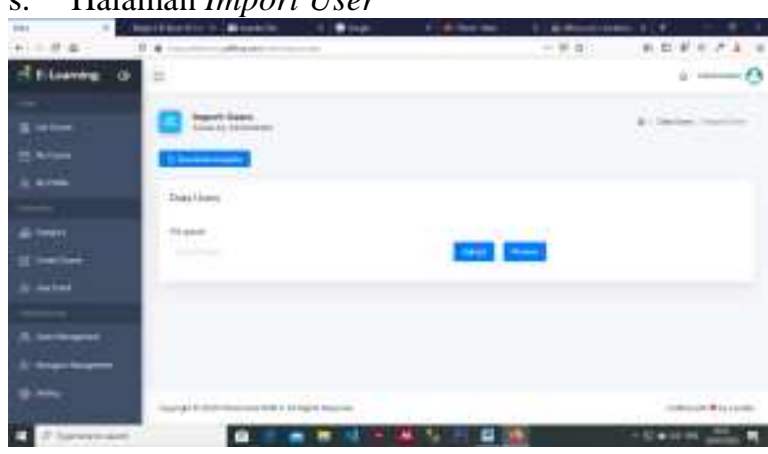

Sumber: Hasil Penelitian (2020)

Gambar 22. Halaman Import User

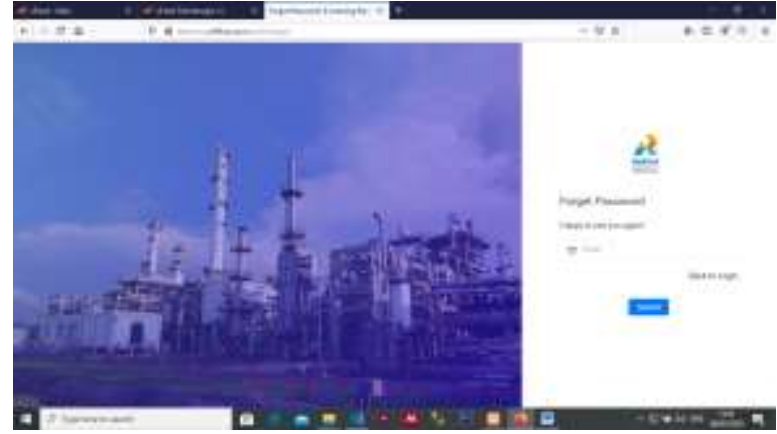

Sumber: Hasil Penelitian (2020)

Gambar 23. Halaman Lupa Password

u. Halaman My Profile

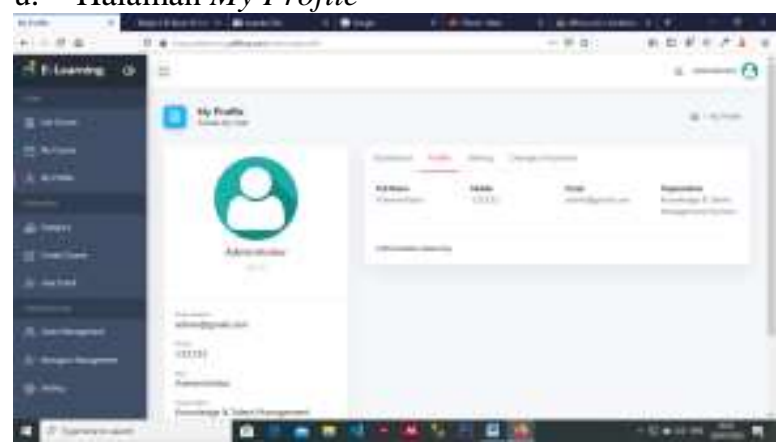

Sumber: Hasil Penelitian (2020)

Gambar 24. Halaman My Profile

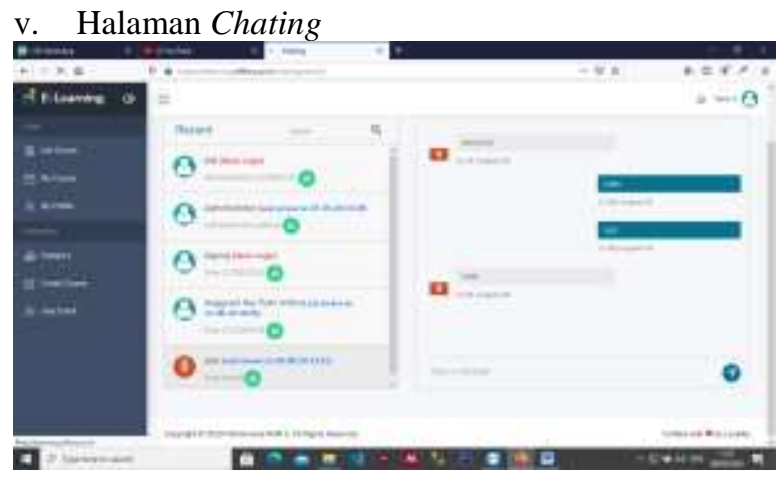

Sumber: Hasil Penelitian (2020)

Gambar 25. Halaman Chating

5. Spesifikasi Hardware dan Software

Untuk dapat mengakses web atau learning management system ini dibutuhkan spesifikasi hardware dan software sebagai berikut:

\begin{tabular}{|c|l|l|}
\multicolumn{2}{|c|}{ Tabel 2. Spesifikasi Hardware dan Software } \\
\hline No. & \multicolumn{1}{|c|}{ Kebutuhan } & \multicolumn{1}{c|}{ Keterangan } \\
\hline 1 & Sistem Operasi & $\begin{array}{l}\text { Windows XP atau } \\
\text { diatasnya }\end{array}$ \\
\hline 2 & Processor & $\begin{array}{l}\text { Intel Core 2 duo atau } \\
\text { diatasnya }\end{array}$ \\
\hline
\end{tabular}

t. Halaman Lupa Password 


\begin{tabular}{|c|l|l|}
\hline 3 & RAM & 2048 MB atau diatasnya \\
\hline 4 & Harddisk & 320 GB atau diatasnya \\
\hline 5 & Browser & $\begin{array}{l}\text { Google Chrome, Opera, } \\
\text { Internet Explorer, } \\
\text { Mozila (Recommended) }\end{array}$ \\
\hline
\end{tabular}

Sumber: Hasil Penelitian (2020)

\section{KESIMPULAN DAN SARAN}

1. Kesimpulan

Berdasarkan pembahasan yang telah dijelaskan pada bab sebelumnya tentang learning management system dapat ditarik kesimpulan antara lain sebagai berikut:

a. Dengan hadirnya learning management system ini dapat mempermudah peserta maupun trainer dalam melaksanakan pelatihan tanpa harus terhalang jarak.

b. Mempermudah peserta training dalam mengingat kembali materi yang telah disampaikan oleh trainer.

c. Materi yang disimpan oleh trainer menjadi lebih terstruktur.

d. Mempermudah trainer dalam mengoreksi test yang telah dilaksanakan, karena proses koreksi sudah dilakukan oleh sistem.

\section{Saran}

Adapun saran yang dapat penulis sampaikan untuk proses pengembangan sistem kedepannya agar sistem menjadi lebih baik antara lain sebagai berikut:

\section{a. Aspek Sistem}

Untuk membuat sistem ini menjadi lebih interaktif, bisa menambahkan fitur forum dan pesan pada chat mungkin bisa di enkripsi agar lebih aman.

\section{b. Aspek Penelitian}

Untuk penelitian selanjutnya penulis menyarankan untuk menguji konkurensi pengguna terhadap sistem ini, karena learning management system ini memungkinkan user atau pengguna masuk atau login secara bersamaan.

\section{c. Aspek Managerial}

Untuk penggunaan yang efektif dan efisien diperlukan pelatihan kepada pengguna tentang bagaimana sistem ini digunakan.
AKADEMIK BERBASIS WEB ( studi kasus: SMA Swasta Harapan I Medan ). Jurnal Sistem Informasi, 1(2), 23-32.

Dharmawan, S. S. (2020). Mengenal Learning Management System. Retrieved April 9, 2020, from Kompasiana website: https://www.kompasiana.com/sarah33150/5e2 7df57d541df47857cf962/mengenal-learningmanagement-system

Ependi, U. (2018). Implementasi Model Scrum pada Sistem Informasi Seleksi Masuk Mahasiswa Politeknik Pariwisata Palembang. Jurnal Informatika: Jurnal Pengembangan IT, 3(1), 49-55. https://doi.org/10.30591/JPIT.V3I1.640

PT Rekayasa Industri. (2019). PT Rekayasa Industri. Retrieved April 7, 2020, from PT. Rekayasa Industri website: http://www.rekayasa.com

Puspitasari, D. (2016). SISTEM INFORMASI PERPUSTAKAAN SEKOLAH BERBASIS WEB. Pilar Nusa Mandiri, 12(2). Retrieved from

https://media.neliti.com/media/publications/22 7462-sistem-informasi-perpustakaan-sekolahbe-90754734.pdf

Romindo. (2017). Perancangan Aplikasi E-Learning Berbasis Web Pada SMA Padamu Negeri Medan. Jurnal \& Penelitian Teknik Informatika, Volume $2 \quad N, 6$. https://doi.org/10.1007/s13398-014-0173-7.2

Swara, G. Y. Kom. M., \& Pebriadi, Y. (2016). Rekayasa Perangkat Lunak Pemesanan Tiket Bioskop Berbasis Web. Jurnal TEKNOIF, 4(2), 27-39.

Teuku Fadjar Shadek, R. S. (2017). Pengembangan Aplikasi Sistem E-Learning Pada Seluruh Mata Kuliah Dengan Menggunakan Program Hypertext Prepocessor ( Php ) Dalam Rangka Peningkatan Mutu Proses Dan Hasil Pembelajaran. Jurnal ProTekInfo, 4, 1-18.

Wibowo, A. T., Akhlis, I., \& Nugroho, S. E. (2015). Pengembangan LMS (Learning Management System) Berbasis Web untuk Mengukur Pemahaman Konsep dan Karakter Siswa. Scientific Journal of Informatics, 1(2), 127137. https://doi.org/10.15294/sji.v1i2.4019

\section{REFERENSI}

Dafitri, H., \& Elsera, M. (2017). RANCANG BANGUN SISTEM INFORMASI

36 Rancang Bangun Learning Management System Menggunakan Framework CodeIgniter Pada 